\title{
Posebne populacije bolesnika: Udružena ishemijska bolest srca i šećerna bolest
}

\author{
Milan Nedeljković, Zlatko Mehmedbegović \\ Klinika za kardiologiju, Klinički centar Srbije; Medicinski fakultet, Univerzitet u Beogradu
}

\section{Klinička perspektiva}

Proporcionalni udeo pacijenata sa šećernom bolešću (DM) se povećava kod pacijentima sa koronarnom bolešću, kao i broj procedura na koronarnim arterijama. ${ }^{1}$ Specifični problemi koji su udruženi sa revaskularizacijom ovih pacijenata su pre svega reintervencije zbog restenoza i okluzija arterija, a i sam višegodišnji mortalitet je veći u odnosu na opštu populaciju. ${ }^{2}$

\section{Medikamentna terapija pacijenata sa DM i kardiovaskularni rizik}

Bolesnici sa šećernom bolešću (DM) su pod povećanim kardiovaskularnim rizikom za neželjene događaje koji je srazmeran riziku za sekundarne događaje kod osoba koji nemaju DM, a već su lečeni pacijenti sa istorijom KV događaja. ${ }^{3}$ Kao takvima optimalna medikamentna terapija treba da obuhvata ne samo dobru regulaciju šećera u krvi već i krvnog pritiska, nivoa lipida, kao i optimalnu antitrombocitnu terapiju. Intenzitet terapije delom treba individualizovati prema kliničkom riziku pacijenta, procenjenom upotrebom nekog od kalkulatora rizika (Framingham risk score (http://hp2010.nhlbihin.net/atpiii/calculator.asp? usertype=prof), UKPDS risk engine(http://www. dtu.ox.ac.uk/riskengine/)). Ukoliko izmene životnog stila ne dovedu do redukcije pritiska ispod 140/80 $\mathrm{mmHg}$ (ili ispod 130/80 mmHg ukoliko postoje oštećenja ciljnih organa - bubrega, oka ili CNS-a), savetuje se primena medikamentne terapije. Kao terapija prvog izbora preporučuje se jednodnevna doza ACE inhibitori (ARB u slučaju intolerancije), dok se kao druga terapija preporučuju blokatori kalcijumskih kanala (CCB) i/ili diuretik. Nakon neuspeha ove terapije, dodatnu regulaciju krvnog protoska ostvariti sa alfa-, beta-blokerom ili K-štedećim diuretikom.

Procena lipidnog statusa bi trebalo da uključi i parametre metaboličkog rizika i obim struka. Ukoliko izmene životnog stila i dijetetske navike ne daju pozitivne efekte potrebno je primeniti terapiju lekovima, pre svega statinima. S obzirom na to da ne postoji siguran dovoljno „nizak“ nivo lipida koji bi sprečio aterosklertske procese, ciljne vrednosti kojima bi trebalo težiti nisu jasno definisane i razlikuju se od preporuka do preporuka, ali je sigurno da dozu statina treba maksimalno titrirati, ili sve dok vrednost ukupnog holesterola nije $<4.0 \mathrm{mmol} / \mathrm{L}$, odnosno <LDL $2.0 \mathrm{mmol} / \mathrm{L}$. Ukoliko je to nemoguće postići, razmotriti dodavanje novijeg i efikasnijeg statina ${ }^{4}$ ili eze- timiba ${ }^{5}$. Prepisivanje fenofibrata se savetuje ukoliko je vrednost triglicerida između 2,3-4,5 mmol/L uprkos terapiji statinima a rizik od KV neželjenih događaja je visok. Rutinska primena omega 3 masnih kiselina i preparata nikotinske kiseline nema svoju jasnu naučnu osnovu.

Antitrombocitna terapija (AT), aspirin i klopidogrel, s obzirom na povećan rizik bolesnika sa DM, ima posebno mesto u terapiji. Primena AT lekova u sekundarnoj prevenciji i nakon KV događaja je ista kao i za bolesnike bez DM i ne treba je posebno diskutovati. U slučaju primarne prevencije uzimajući u obzir visoku verovatnoću neželjenog događaja kod DM, primena aspirina i/ili klopidogrela je diskutabilna i nema mnogo dokaza za i protiv. Trenutne preporuke ne savetuju rutinsku primenu aspirina, ali klinička praksa govori da aspirin jednom dnevno za pacijente preko 50 godina može imati korist u prevenciji ishemijskih događaja, dok se za mlađe od 50 savetuje primena samo u slučaju postojanja neprihvatljivo visokog rizika za KV događaje (metabolički sindrom, pušenje, jaka nasledna osnova, hipertenzija). Zajednička primena oba leka se ne savetuje u sklopu primarne prevencije.

\section{Opravdanost revaskularizacionog pristupa kod pacijenata sa DM}

Prednost revaskularizacione strategije u odnosu na samo optimalnu medikamentnu terapiju (OMT) kod pacijenata sa stabilnom anginom pectoris i DM potvrđena je u BARI 2D studiji gde je u celini pokazano nakon 5 godina praćenja da nije bilo razlike u smrtnosti, infarktu miokarda i šlogu između OMT $(12,2 \%)$ i grupe sa revaskularizacijom (PCl i CABG zajedno, 11,7\%). Međutim, u PCI grani studije nije uočena prednost perkutanog pristupa $\mathrm{u}$ odnosu na samo OMT, dok je u hirurškoj grupi zabeleženo statistički značajno manje događaja u odnosu na pacijente lečene samo sa OMT $(22,4 \%$ vs $31,5 \%){ }^{6}$

U populaciji akutnih koronarnih sindroma bez ST elevacije, generalna korist je vezana pre svega za ranu revaskularizaciju, s tim što je korist ipak bila nešto veća u grupi sa DM, što je i zaključak studija FRICS-S i TACTICSTIMI 18. 7,8

Kod STEMI pacijenata, većina randomizovanih studija, kao i zaključak meta-analize PCAT-2, je pokazao postojanje koristi od revaskularizacije u odnosu na trombolitičku terapiju, kako za pacijente sa, tako i za pacijente bez DM. Pacijenti sa DM su imali relativnu redukciju rizika od 51\%, revaskularizacijom u odnosu na OMT. ${ }^{9}$ 


\section{PCI ili CABG kao tip revaskularizacione terapije}

Većina randomizovanih studija su potvrdile prednost CABG u odnosu na $\mathrm{PCl}$ u pogledu ponovne revaskularizacije kod pacijenata sa DM. Povezanost restenoze i DM je jasna i signifikantna, dok u pogledu mortaliteta najčešće nema razlike u izboru terapijske revaskularizacione strategije. ${ }^{10}$ AWESOME studija u trogodišnjem praćenju kod pacijenata sa visokim rizikom randomizovanih $u 2$ grupe nije pokazala razlike u preživljavanju. Isto tako ni CARDia studija u 1 godini praćenja nije našla razliku u ukupnom MACE-u (smrt, IM i šlog), između PCI (13\%) i CABG $(10,5 \%)$, dok je u ponovnoj revaskularizaciji razlika bila evidentna u korist CABG ( $2 \%$ vs $11,8 \%$; $p<0.001)^{11}$. Takođe, na drugoj strani, registri (New York registry) takođe nisu pokazali jasnu razliku već samo postojanje blagog trenda u pogledu smanjene smrtnosti i IM kod pacijenata lečenih hirurškim pristupom u odnosu na perkutani kod pacijenata sa DM. ${ }^{12}$

\section{PCI: DES vs BMS}

Slično kao i u opštoj populaciji, DES imaju prednost u odnosu na BMS u pogledu redukcije učestalosti ponovne revaskularizacije, kao što je velika meta-analiza na 3852 pacijenta sa DM pokazala (SES OR 0.29, PES OR $0.38)^{13}$. Neophodnost dvojne atniagregacione terapije $u$ trajanju od minimum 6 meseci je takođe istaknuta, jer $u$ suprotnom mortalitet kod DES-a prevazilazi korist od njihove upotrebe. Razlike između različitih tipova polimera i antiproliferativnih lekova između DES-ova nisu uočene na velikom broju pacijenata.

\section{CABG: tip operacije}

Pacijenti sa DM najčešće zahtevaju veliki broj graftova s obzirom na ekstenzivnost promena na koronarnim arterijama. Upotreba arterijskog grafta ima prednost u odnosu na venske, ali dokaza da je bilateralna arterijska revaskularizacija superiornija u odnosu na unilateralnu nema dovoljno, izuzev opservacionih studija. ${ }^{14} \mathrm{U}$ jednoj nerandomizovanoj studiji bilateralna arterijska revaskularizacija nije imala bolje preživljavanje u odnosu na PCl, nakon 5 godina praćenja. ${ }^{15}$ lako je DM faktor rizika za nastanak medijastinitisa i komplikacija vezanih za upotrebu obe grudne arterije, jasnih dokaza za sad nema.

\section{Dvojna antitrombocitna terapija (DAT)}

Primena DAT kod pacijenata sa DM se ne razlikuje u odnosu na opštu populaciju i važe iste preporuke povodom dužine i doze davanja. ${ }^{16,17,18}$ lako su neke ranije studije pokazale interakciju kod pacijenata sa DM i GPIIb/ Illa terapije sa smanjenim efektom, slični nalazi nisu uočeni u slučaju da se primenjuje i preporučena doza tienopiridina. ${ }^{16}$ Rutinska administracija GPIIb/IIla periproceduralno nema svoje racionalno opravdanje u dokazima.

\section{Konkomitantna metabolička terapija}

Upotreba metformina može kod pacijenata sa oštećenjem bubrežne funkcije dovesti do razvoja laktične acidoze, te su postojeće preporuke da se metformin kod bolesnika sa DM i/ili oštećenom bubrežnom funkcijom obustavi na dan primene i narednih 24-48 h nakon procedure. Za glitazone se vezuje nešto manja učestalost restenoze ali i veća incidenca srčane slabosti. Upotreba insulina u toku PCl ili CABG nema posebne specifičnosti. Primena glukoze, insulina i kalijuma (GIK) pokazala je prednost kod CABG-a sa manjom učestalošću komplikacija (AF, infekcija rane, oštećenje miokarda, dužina bolničkog ostanka). ${ }^{19-21}$ lako uska kontrola nivoa šećera u krvi ima racionalnu osnovu, u NICE-SUGAR studiji zabeležena je veća učestalost hipoglikemijskih epizoda, sa povećanjem mortaliteta na 90 dana. ${ }^{22}$ (Tabela 1)

Tabela 1. Specifičnosti revaskularizacije miokarda kod bolesnika sa dijabetesom

\begin{tabular}{|c|c|c|c|}
\hline & $\begin{array}{c}\text { Klasa } \\
\text { preporuke }\end{array}$ & $\begin{array}{l}\text { Nivo } \\
\text { dokaza }\end{array}$ & Ref \\
\hline $\begin{array}{l}\text { Kod bolesnika sa STEMI primarna PCI je metoda izbora ukoliko može biti izvedena } \\
\text { u preporučenom vremenskom okviru }\end{array}$ & I & A & 23 \\
\hline $\begin{array}{l}\text { Kod bolesnika sa stabilnom ekstenzivnom koronarnom bolešću revaskularizacija } \\
\text { je indikovana kako bi se smanjila učestalost MACE }\end{array}$ & I & A & 24 \\
\hline $\begin{array}{l}\text { Upotreba DES-a je indikovana kako bi se smanjila učestalost restenoze i ponovne } \\
\text { revaskularizacije }\end{array}$ & I & A & 25 \\
\hline Kod bolesnika na metforminu bubrežna funkcija bi trebalo da se budno prati & I & C & 1 \\
\hline $\begin{array}{l}\text { Hirurška revaskularizacija ima prednost u odnosu na } \mathrm{PCl} \text { ukoliko težina koronarne } \\
\text { bolesti opravdava hirurški pristup, a očekivani benefit i dužina života prevazilaze } \\
\text { rizik hirurškog pristupa }\end{array}$ & Ila & B & $\begin{array}{l}2,12 \\
11,26\end{array}$ \\
\hline Kod bolesnika sa HBI metformin bi trebalo stopirati $48 \mathrm{~h}$ pre procedure & $\mathrm{Ilb}$ & $\mathrm{C}$ & / \\
\hline Sistematska upotreba GIK u toku revaskularizacione terapije nije & III & B & $\begin{array}{l}19,20 \\
22\end{array}$ \\
\hline
\end{tabular}




\section{Literatura:}

1. Ryden L., Standl E., Bartnik M., et al. Guidelines on diabetes, prediabetes, and cardiovascular diseases: executive summary. The Task Force on Diabetes and Cardiovascular Diseases of the European Society of Cardiology (ESC) and of the European Association for the Study of Diabetes (EASD). Eur Heart J., 2007; 28: 88-136.

2. Hlatky MA, Boothroyd DB, Bravata DM, et al. Coronary artery bypass surgery compared with percutaneous coronary interventions for multivessel disease: a collaborative analysis of individual patient data from ten randomised trials. Lancet 2009; 373 : 1190-1197.

3. Haffner SM, Lehto S., Ronnemaa T., et al. Mortality from coronary heart disease in subjects with type 2 diabetes and in nondiabetic subjects with and without prior myocardial infarction. N Engl J Med 1998; 339 (4): 229-234.

4. National Institute for Health and Clinical Excellence. Statins for the prevention of cardiovascular events in patients at increased risk of developing cardiovascular disease or those with established cardiovascular disease (TA94). London: NICE, 2006.

5. National Institute for Health and Clinical Excellence. Ezetimibe for the treatment of primary (heterozygous familial and non-familial) hypercholesterolaemia (TA132). London: NICE, 2007.

6. Frye RL, August P., Brooks MM, et al. A randomized trial of therapies for type 2 diabetes and coronary artery disease. $\mathrm{N}$ Engl J Med 2009; 360: 2503-2515.

7. Lagerqvist B., Husted S., Kontny F., Stahle E., Swahn E., Wallentin L. 5-year outcomes in the FRISC-II randomised trial of an invasive versus a non-invasive strategy in non-ST-elevation acute coronary syndrome: a follow-up study. Lancet 2006;368:998-1004.

8. Cannon CP, Weintraub WS, Demopoulos LA, et al. Comparison of early invasive and conservative strategies in patients with unstable coronary syndromes treated with the glycoprotein IIb/ IIIa inhibitor tirofiban. N Engl J Med 2001; 344: 1879-1887.

9. Timmer JR, Ottervanger JP, de Boer MJ, et al. Primary percutaneous coronary intervention compared with fibrinolysis for myocardial infarction in diabetes mellitus: results from the Primary Coronary Angioplasty vs Thrombolysis-2 trial. Arch Intern Med 2007; 167: 1353-1359.

10. Hlatky MA, Boothroyd DB, Bravata DM, et al. Coronary artery bypass surgery compared with percutaneous coronary interventions for multivessel disease: a collaborative analysis of individual patient data from ten randomised trials. Lancet 2009; 373 : 1190-1197.

11. Sedlis SP, Morrison DA, Lorin JD, et al. Percutaneous coronary intervention versus coronary bypass graft surgery for diabetic patients with unstable angina and risk factors for adverse outcomes with bypass: outcome of diabetic patients in the AWESOME randomized trial and registry. J Am Coll Cardiol 2002; 40: 1555-1566.

12. Hannan EL, Wu C., Walford G., et al. Drug-eluting stents vs. coronary-artery bypass grafting in multivessel coronary disease. $\mathrm{N}$ Engl J Med 2008; 358: 331-341.
13. Stettler C., Allemann S., Wandel S., et al. Drug eluting and bare metal stents in people with and without diabetes: collaborative network meta-analysis. BMJ 2008; 337:a1331. ESC/EACTS Guidelines 2551

14. Taggart DP, D'Amico R., Altman DG. Effect of arterial revascularisation on survival: a systematic review of studies comparing bilateral and single internal mammary arteries. Lancet 2001; 358: 870-875.

15. Locker C., Mohr R., Lev-Ran O., et al. Comparison of bilateral thoracic artery grafting with percutaneous coronary interventions in diabetic patients. Ann Thorac Surg 2004; 78: 471-475.

16. Giugliano RP, White JA, Bode C., et al. Early versus delayed, provisional eptifibatide in acute coronary syndromes. N Engl J Med 2009; 360: 2176-2190.

17. Primary versus tenecteplase-facilitated percutaneous coronary intervention in patients with ST-segment elevation acute myocardial infarction (ASSENT-4 PCI): randomised trial. Lancet 2006; 367: 569-578.

18. Ellis SG, Tendera M., de Belder M A, et al. Facilitated $\mathrm{PCl}$ in patients with ST-elevation myocardial infarction. N Engl J Med 2008; 358: 2205-2217.

19. Mellbin LG, Malmberg K, Norhammar A, Wedel H, Ryden L. The impact of glucose lowering treatment on long-term prognosis in patients with type 2 diabetes and myocardial infarction: a report from the DIGAMI 2 trial. Eur Heart J., 2008; 29: 166-176.

20. Cheung NW, Wong VW, McLean M. The Hyperglycemia: Intensive Insulin Infusion in Infarction (HI-5) study: a randomized controlled trial of insulin infusion therapy for myocardial infarction. Diabetes Care 2006; 29: 765-770.

21. Mehta SR, Yusuf S., Diaz R., et al. Effect of glucose-insulin-potassium infusion on mortality in patients with acute ST-segment elevation myocardial infarction: the CREATE-ECLA randomized controlled trial. JAMA 2005; 293: 437-446.

22. Finfer S., Chittock DR, Su SY, et al. Intensive versus conventional glucose control in critically ill patients. N Engl J Med 2009; 360: 1283-1297.

23. Timmer JR, Ottervanger JP, de Boer MJ, et al. Primary percutaneous coronary intervention compared with fibrinolysis for myocardial infarction in diabetes mellitus: results from the Primary Coronary Angioplasty vs Thrombolysis-2 trial. Arch Intern Med 2007; 167: 1353-1359.

24. Frye RL, August P., Brooks MM, et al. A randomized trial of therapies for type 2 diabetes and coronary artery disease. $N$ Engl J Med 2009; 360: 2503-2515.

25. Stettler C., Allemann S., Wandel S., et al. Drug eluting and bare metal stents in people with and without diabetes: collaborative network meta-analysis. BMJ 2008; 337:a1331. ESC/EACTS Guidelines 2551.

26. Locker C., Mohr R., Lev-Ran O., Uretzky G., Frimerman A., Shaham Y., Shapira I.

27. Comparison of bilateral thoracic artery grafting with percutaneous coronary interventions in diabetic patients. Ann Thorac Surg 2004; 78: 471-475. 